EXTENDED REPORT

\title{
Effect of nitric oxide on mitochondrial respiratory activity of human articular chondrocytes
}

\author{
E Maneiro, M J López-Armada, M C de Andres, B Caramés, M A Martín, A Bonilla, P del Hoyo, \\ F Galdo, J Arenas, F J Blanco
}

See end of article for authors' affiliations

.....................

Correspondence to: Dr F J Blanco, Laboratorio de Investigación, Servicio de Reumatología, Complejo Hospitalario Universitario Juan Canalejo, C/Xubias, 84, 15006-A Coruña, Spain; Francisco_Blanco@ canalejo.org

Accepted 22 July 2004

\begin{abstract}
Objective: To investigate the effect of nitric oxide (NO) on mitochondrial activity and its relation with the apoptosis of human articular chondrocytes.

Materials and methods: Mitochondrial function was evaluated by analysing respiratory chain enzyme complexes, citrate synthase (CS) activities, and mitochondrial membrane potential $(\Delta \psi \mathrm{m})$. The activities of the mitochondrial respiratory chain (MRC) complexes (complex I: NADH CoQ 1 reductase, complex II: succinate dehydrogenase, complex III: ubiquinol cytochrome c reductase, complex IV: cytochrome c oxidase) and CS were measured in human articular chondrocytes isolated from normal cartilage. The $\Delta \psi \mathrm{m}$ was measured by $5,5^{\prime}, 6,6^{\prime}$-tetracholoro-1,1',3,3'-tetraethylbenzimidazole carbocyanide iodide (JC-1) using flow cytometry. Apoptosis was analysed by flow cytometry. The mRNA expression of caspases was analysed by ribonuclease protection analysis and the detection of protein synthesis by western blotting. Sodium nitroprusside (SNP) was used as an NO compound donor.

Results: SNP at concentrations higher than $0.5 \mathrm{mmol} / \mathrm{l}$ for 24 hours induced cellular changes characteristic of apoptosis. SNP elicited mRNA expression of caspase-3 and caspase-7 and down regulated bcl-2 synthesis in a dose and time dependent manner. Furthermore, $0.5 \mathrm{mM}$ SNP induced depolarisation of the mitochondrial membrane at 5, 12, and 24 hours. Analysis of the MRC showed that at 5 hours, $0.5 \mathrm{mM}$ SNP reduced the activity of complex IV by $33 \%$. The individual inhibition of mitochondrial complex IV with azide modified the $\Delta \psi \mathrm{m}$ and induced apoptosis.

Conclusions: This study suggests that the effect of $\mathrm{NO}$ on chondrocyte survival is mediated by its effect on complex IV of the MRC.
\end{abstract}

O steoarthritis (OA) is the most common cartilage and joint disease related to age. ${ }^{2}$ Activated chondrocytes produce extracellular matrix degrading enzymes; this process is associated with enhanced cell proliferation and death. In the cartilage of humans with OA, increased numbers of chondrocytes have been found to undergo apoptosis. ${ }^{3}$ Those areas of cartilage containing apoptotic cells showed proteoglycan depletion and, furthermore, the number of apoptotic cells correlated significantly with the severity of $\mathrm{OA}^{4}{ }^{4}$ These results all suggest that apoptotic death of articular chondrocytes is implicated in the pathogenesis of human OA.

Mitochondria are complex organelles that oxidise a wide range of metabolic intermediates. It has been reported that in living cells, these organelles have a characteristic appearance that is dependent on the tissue type and the oxidative state of the cell. Multienzyme complexes located in both the inner mitochondrial membrane and the mitochondrial matrix oxidise tricarboxylic acid cycle intermediates derived from primary nutrients. ATP is generated by the activity of an electrogenic proton pump that spans the inner mitochondrial membrane. Mitochondrial impairment and defective oxidative phosphorylation have been linked to some human disorders. ${ }^{56}$ The analysis of mitochondrial respiratory chain (MRC) activity in OA cells showed a significant decrease in complexes II and III in comparison with normal chondrocytes. ${ }^{7}$ Mitochondria are important in regulating both caspase dependent and caspase independent apoptotic pathways. ${ }^{8-12}$ The classic signs of cell death are preceded by mitochondrial alterations $^{13-15}$ and include a loss of mitochondrial membrane potential $(\Delta \psi \mathrm{m}),{ }^{10-12}{ }^{15}$ a decrease in energy production, ${ }^{14}{ }^{16}$ an increase in the permeability of the mitochondrial membrane, ${ }^{17}$ and a release of pro-apoptotic factors such as cytochrome $c .^{18} 19$

Nitric oxide (NO) is a messenger implicated in both chondrocyte death and protection from oxidative damage induced on chondrocytes. ${ }^{40-25} \mathrm{NO}$ synthesis is enhanced in OA cartilage. ${ }^{2021}$ A variety of NO donors have been shown to suppress energy production by mitochondrial respiration in different cell types. ${ }^{26-30}$ In chondrocytes, two studies have shown that NO donors suppress respiration and ATP generation, suggesting a contribution to matrix loss and cartilage mineralisation. ${ }^{31}{ }^{32}$ However, the precise mechanism by which NO compound donors block mitochondrial respiration and ATP production, and by which they induce apoptosis, is unknown. ${ }^{33}$

This study was designed to investigate the effect of NO on the mitochondrial activity of human articular chondrocytes, and to analyse whether its effect on mitochondrial activity is the mechanism by which it induces apoptosis. The results suggest that sodium nitroprusside (SNP; an NO donor compound) induces chondrocyte apoptosis because it reduces the activity of complex IV of the MRC.

Abbreviations: CS, citrate synthase; DMEM, Dulbecco's modified Eagle's medium; $\Delta \psi \mathrm{m}$, mitochondrial membrane potential; JC-1, $5,5^{\prime}, 6,6^{\prime}$ 'tetrachloro-1, 1', 3, 3' -tetraethylbenzimidazole carbocyanide iodide; KP, phosphate buffer; MOPS, 4-morpholinepropane sulphonic acid; $M R C$, mitochondrial respiratory chain; $\mathrm{NaN}_{3}$, sodium azide; $\mathrm{NO}$, nitric oxide; OA, osteoarthritis; PBS, phosphate buffered saline; PI, propidium iodide; RNS, reactive nitrogen species; ROS, reactive oxygen species; RPA, ribonuclease protection analysis; SDS, sodium dodecyl sulphate; SNP, sodium nitroprusside, TNF $\alpha$, tumour necrosis factor $\alpha$ 


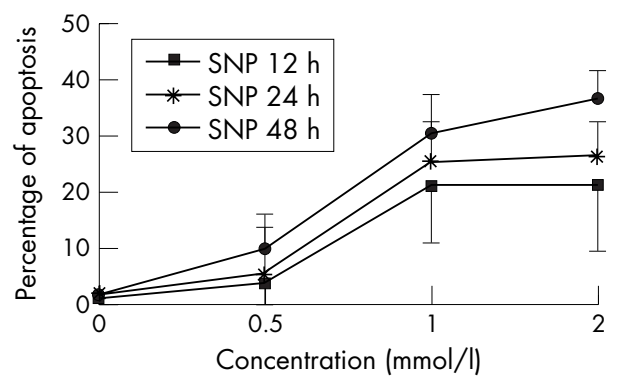

Figure 1 Kinetics of the NO effect (SNP) on chondrocyte apoptosis. Cells $\left(5 \times 10^{5}\right.$ normal human chondrocytes), treated with SNP at different concentrations for 12,24 , and 48 hours were fixed in $70 \%$ ethanol at $4^{\circ} \mathrm{C}$, then washed and incubated with RNase and PI for 15 minutes at room temperature in the dark. Data are expressed as a percentage of apoptotic (hypodiploid) nuclei. The graph shows that SNP dose dependently induces chondrocyte apoptosis.

\section{MATERIALS AND METHODS}

\section{Primary culture of chondrocytes}

Normal human knee cartilage was obtained at necropsy from 30 adult cadavers (mean (SD) age 59.7 (21.0) years) who had no history of joint disease and who had macroscopically normal cartilage. Human OA cartilage was obtained from the femoral heads of six patients who were undergoing joint replacement surgery (mean (SD) age 63.5 (7)).

The cartilage surfaces were first rinsed with sterile saline. Scalpels were used to cut vertically from the cartilage surface onto the subchondral bone in parallel sections $5 \mathrm{~mm}$ apart. These cartilage strips were then resected from the subchondral bone. The tissue was incubated at $37^{\circ} \mathrm{C}$ with trypsin for 10 minutes. After removing the trypsin solution, the cartilage slices were treated with type IV collagenase $(2 \mathrm{mg} / \mathrm{ml}$; Sigma, St Louis, MO) for 12-16 hours. Chondrocytes were recovered and plated at high density $\left(4 \times 10^{6}\right.$ per $162 \mathrm{~cm}^{2}$ flask; Costar, Cambridge, MA) in Dulbecco's modified Eagle's medium (DMEM; Life Technologies, Paisley, UK) supplemented with
$100 \mathrm{U} / \mathrm{ml}$ penicillin, $100 \mu \mathrm{g} / \mathrm{ml}$ streptomycin, $1 \%$ glutamine, and 10\% fetal bovine serum (Life Technologies). Experiments without glucose were carried out in DMEM free glucose media (Life Technologies, Paisley, UK). The chondrocyte cultures were incubated at $37^{\circ} \mathrm{C}$ in a humidified gas mixture containing $5 \% \mathrm{CO}_{2}$ balanced with air. Chondrocytes used in these experiments were at confluency in primary culture at $2-3$ weeks. Cell viability was assessed by trypan blue dye exclusion (viability was $>95 \%$ ).

\section{Treatment of chondrocytes with MRC inhibitor}

Sodium azide ( $\mathrm{NaN}_{3}$; Sigma), a mitochondrial inhibitor of complex IV, was added from a 1 M stock solution dissolved in distilled water, after which it was added directly to the culture medium and allowed to incubate for an additional period $(5,12,24$, or 48 hours). This compound was stored as a $1 \mathrm{M}$ stock solution in distilled water at $4^{\circ} \mathrm{C}$.

\section{DNA labelling technique for flow cytometric analysis} Cells were fixed in $70 \%$ ethanol at $4{ }^{\circ} \mathrm{C}$ for 60 minutes, washed, and incubated with RNAse $(50 \mu \mathrm{g} / \mathrm{ml})$ and propidium iodide (PI, $100 \mu \mathrm{g} / \mathrm{ml}$ ) for 15 minutes at room temperature in the dark and then kept at $4^{\circ} \mathrm{C}$. The PI fluorescence of nuclei was measured by flow cytometry on a FACScan (Becton and Dickinson, Mountain View, CA) using a $560 \mathrm{~nm}$ dichromatic mirror and a $600 \mathrm{~nm}$ band pass filter. Data are expressed as a percentage of apoptotic (hypodiploid) nuclei.

\section{Determination of mitochondrial membrane potential $(\Delta \psi \mathrm{m})$}

To measure the $\Delta \psi \mathrm{m}$ of chondrocytes, the fluorescent probe JC-1 $\quad\left(5,5^{\prime}, 6,6^{\prime}\right.$-tetrachloro- $1,1^{\prime}, 3,3^{\prime}$-tetraethylbenzimidazole carbocyanide iodide) was used. JC-1 exists as a monomer at low values of $\Delta \psi \mathrm{m}$ (green fluorescence), while it forms aggregates at a high $\Delta \psi \mathrm{m}$ (red fluorescence). Thus, mitochondria with a normal $\Delta \psi \mathrm{m}$ concentrate JC-1 into aggregates (red fluorescence), but with a de-energised or
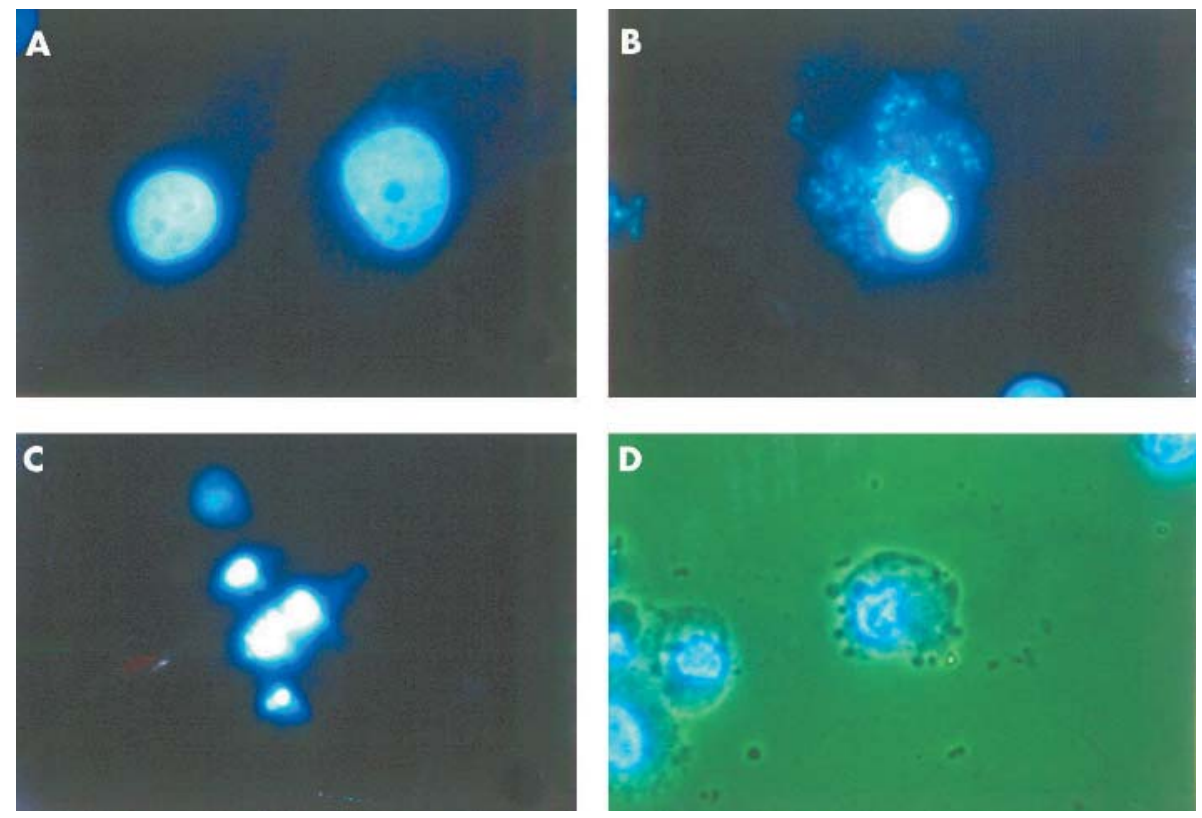

Figure 2 Cellular changes induced by NO on normal human chondrocyłes. 4',6-Dianidino-2-phenylindole dihydrochloride staining analysed by fluorescence microscopy $(A-C)$ and by the combination of fluorescence and light microscopy (D). (A) Untreated cells (control). The normal morphology of a chondrocyte nucleus. (B, C) Cells treated with SNP $(2 \mathrm{mmol} / \mathrm{l})$ for 12 hours. Both panels show the typical morphology of an apoptotic nucleus, condensation (B) and fragmentation (C). (D) Cells treated with SNP (2 mmol/l) for 24 hours, showing simultaneous changes in the cytoplasmic membrane (bubbles) and in the nucleus margination of DNA. 


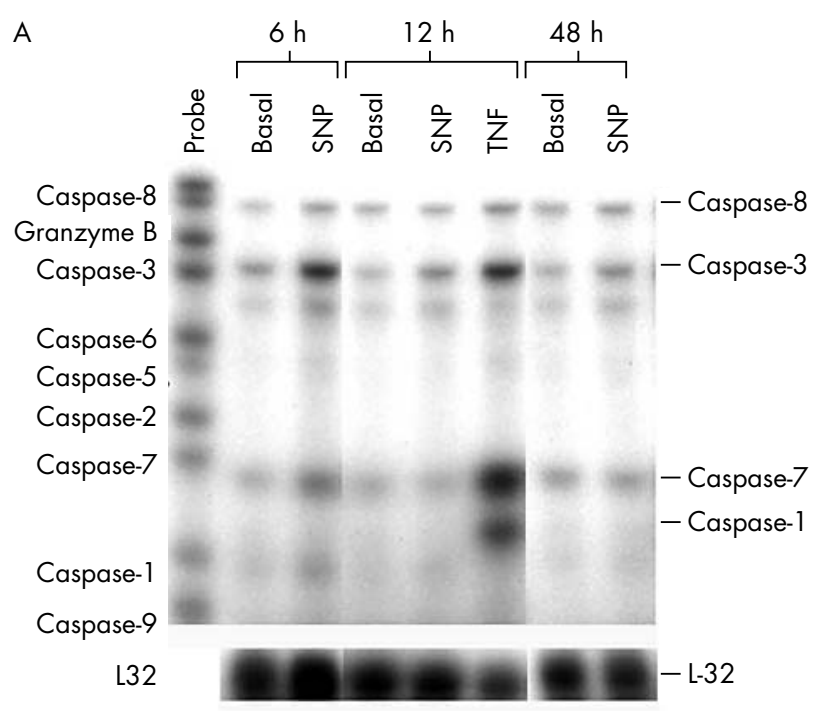

B

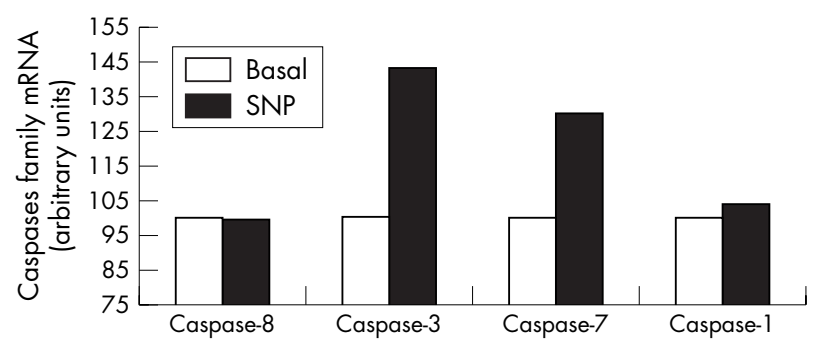

Figure 3 The time course of NO on mRNA expression of the caspases in normal human chondrocytes. (A) Confluent chondrocytic cells were incubated for the indicated time intervals $(6,12$, and 48 hours), both in basal conditions or in the presence of SNP $(0.5 \mathrm{mmol} / \mathrm{l})$ or tumour necrosis factor $\alpha(T N F \alpha, 10 \mathrm{ng} / \mathrm{ml})$. After incubation, total RNA was isolated and the mRNA expression of the caspases was analysed by the RPA as reported in "Materials and methods". This autoradiograph represents a total of three experiments. (B) Densitometric analysis of the bands (at 6 hours of incubation) was conducted by computerised laser densitometry and normalised to the housekeeping L-32 mRNA level. Values are expressed as the percentage over control. TNF $\alpha$ was used as a positive control and as a comparator stimulus.

depolarised $\Delta \psi \mathrm{m}$, JC-1 forms monomers (green fluorescence).

Briefly, chondrocytes $\left(5 \times 10^{5}\right)$ were collected by trypsinisation, washed in phosphate buffered saline (PBS, pH 7.4) and incubated for 15 minutes at $37^{\circ} \mathrm{C}$ with $10 \mu \mathrm{g} / \mathrm{ml} \mathrm{JC}-1$. Cells were pelleted at $200 \mathrm{~g}$ for 5 minutes, washed in PBS, and analysed by flow cytometry using a FACScan and Cell Quest software (Becton Dickinson, Mountain View, CA). The analyser threshold was adjusted on the FSC channel to exclude most of the subcellular debris. Photomultiplier settings were adjusted to detect JC-1 monomer fluorescence signals on the FLl detector (green fluorescence, centred at $\sim 390 \mathrm{~nm}$ ) and JC-1 aggregate fluorescence signals on the FL2 detector (red fluorescence, centred at $\sim 340 \mathrm{~nm}$ ). Data analyses were performed with Paint-a-Gate Pro Software (Becton Dickinson). Mean fluorescence intensity values for FLl and FL2, expressed as relative linear fluorescence channels (arbitrary units scaled from channels 0 to 10000 ), were obtained for all experiments. In each experiment at least 20000 events were analysed. The relative ratio of aggregate to monomer (red/green) fluorescence intensity values was used for data presentation.
Measurement of the MRC complex activities in digitonin permeabilised chondrocytes

Chondrocytes (at least $10 \times 10^{6}$ ) were collected by trypsinisation, washed with PBS, and sedimented at $150 \mathrm{~g}$ for 5 minutes at $4^{\circ} \mathrm{C}$. The pellet was resuspended in $2 \mathrm{ml}$ of ice cold solution containing $20 \mathrm{mM}$ 4-morpholinepropane sulphonic acid (MOPS), $0.25 \mathrm{M}$ sucrose, and $200 \mu \mathrm{g}$ of digitonin, per $5 \times 10^{6}$ cells. After 5 minutes' incubation on ice, the suspension was centrifuged at $5000 \mathrm{~g}$ for 3 minutes at $4^{\circ} \mathrm{C}$. The pellet was treated with $1.5 \mathrm{ml}$ of $20 \mathrm{mM}$ MOPS, $0.25 \mathrm{M}$ sucrose, and $1 \mathrm{mM}$ EDTA buffer, incubated for 5 minutes and pelleted at $10000 \mathrm{~g}$ for 3 minutes at $4^{\circ} \mathrm{C}$. The pellet was resuspended in $200 \mu \mathrm{l} 10 \mathrm{mM}$ phosphate buffer (KP; pH 7.4), frozen and thawed once, and then mildly sonicated.

Digitonin permeabilised chondrocyte homogenates (10$50 \mu \mathrm{l}$ per $1 \mathrm{ml}$ of test volume) were used to measure the activities of the respiratory chain enzymes and citrate synthase (CS) in a DU-650 spectrophotometer (Beckman Instruments, Palo Alto, CA). Incubation temperatures were $30^{\circ} \mathrm{C}$ for rotenone sensitive NADH coenzyme $\mathrm{Q}_{1}$ reductase (complex I), succinate dehydrogenase (complex II), antimycin sensitive ubiquinol cytochrome $c$ reductase (complex III), and CS, and $38^{\circ} \mathrm{C}$ for cytochrome $c$ oxidase (complex IV). Enzyme activities were normalised to the specific activity of CS to correct for mitochondrial volume.

Briefly, complex I was measured by following the oxidation of NADH at $340 \mathrm{~nm}$ in $20 \mathrm{mM} \mathrm{KP}(\mathrm{pH} 8.0), 200 \mu \mathrm{M} \mathrm{NADH}$, $1 \mathrm{mM} \mathrm{NaN}_{3}, 0.1 \%$ bovine serum albumin-EDTA, and $100 \mu \mathrm{M}$ ubiquinone-1 (Sigma Chemicals), in the absence of rotenone (Calbiochem) and then in the presence of $5 \mu \mathrm{M}$ rotenone so that a rotenone sensitive rate of NADH oxidation could be calculated. Succinate dehydrogenase (complex II) was assessed by following the reduction of 2,6-dichlorophenolindophenol (Sigma Chemicals) at $600 \mathrm{~nm}$ in $50 \mathrm{mM}$ Tris-KP (pH 7), $1.5 \mathrm{mM} \mathrm{KCN,} 100 \mu \mathrm{M}$ 2,6-dichlorophenolindophenol, and $32 \mathrm{mM}$ succinate (Sigma Chemicals). Complex III was assayed by measuring the reduction of cytochrome $c$ at $550 \mathrm{~nm}$ in $50 \mathrm{mM} \mathrm{KP}(\mathrm{pH} 7.5), 2 \mathrm{mM} \mathrm{NaN}_{3}, 0.1 \%$ bovine serum albumin-EDTA, $50 \mu \mathrm{M}$ cytochrome $c$ (Roche), and $50 \mu \mathrm{M}$ decyl-ubiquinol (Sigma Chemicals) in the absence of antimicyn A (Sigma Chemicals) and then in the presence of $0.01 \mathrm{mg} / \mathrm{ml}$ antimycin A, so that an antimicyn A sensitive rate of cytochrome $c$ reduction could be calculated. Complex IV was measured by following the oxidation of reduced cytochrome $c$ at $550 \mathrm{~nm}$ in $10 \mathrm{mM} \mathrm{KP}(\mathrm{pH} \mathrm{7})$ and $80 \mu \mathrm{M}$ reduced cytochrome (freshly prepared before each experiment by adding sodium dithionite (Sigma Chemicals)). CS was evaluated at $420 \mathrm{~nm}$ in $75 \mathrm{mM}$ Tris $\mathrm{HCl}(\mathrm{pH} 8), 100 \mu \mathrm{M}$ 5,5'-dithiobis-(2-nitrobenzoic) acid (Sigma Chemicals), $350 \mu \mathrm{g} / \mathrm{ml}$ acetyl-coenzyme A (Sigma Chemicals), $0.5 \mathrm{mM}$ oxaloacetate (Roche), and $0.1 \%$ Triton X-100 (Sigma Chemicals).

\section{RNA isolation and ribonuclease protection analysis (RPA)}

Total RNA was extracted from chondrocytic cells by the guanidine isothiocyanate-phenol-chloroform method. Concentration and purity of the samples were determined by spectrophotometry. The probe preparation for the RPA was carried out according to the instructions of the manufacturer (BD Pharmingen, Heidelberg, Germany). Briefly, single strand antisense RNA probes, labelled with $\alpha-\left[{ }^{32} \mathrm{P}\right] \mathrm{CTP}$ (Amersham, Buckinghamshire, UK), were synthesised from linearised plasmids using T7 RNA polymerase (BD Pharmigen). Approximately $10^{6} \mathrm{cpm}$ of probes were hybridised overnight at $56^{\circ} \mathrm{C}$ with $10-12 \mu \mathrm{g}$ of total RNA in $10 \mu \mathrm{l}$ of hybridisation buffer. Unhybridised RNA was digested for 45 minutes at $30^{\circ} \mathrm{C}$ in $100 \mu \mathrm{l}$ RNAse solution. Then, $18 \mu \mathrm{l}$ of 

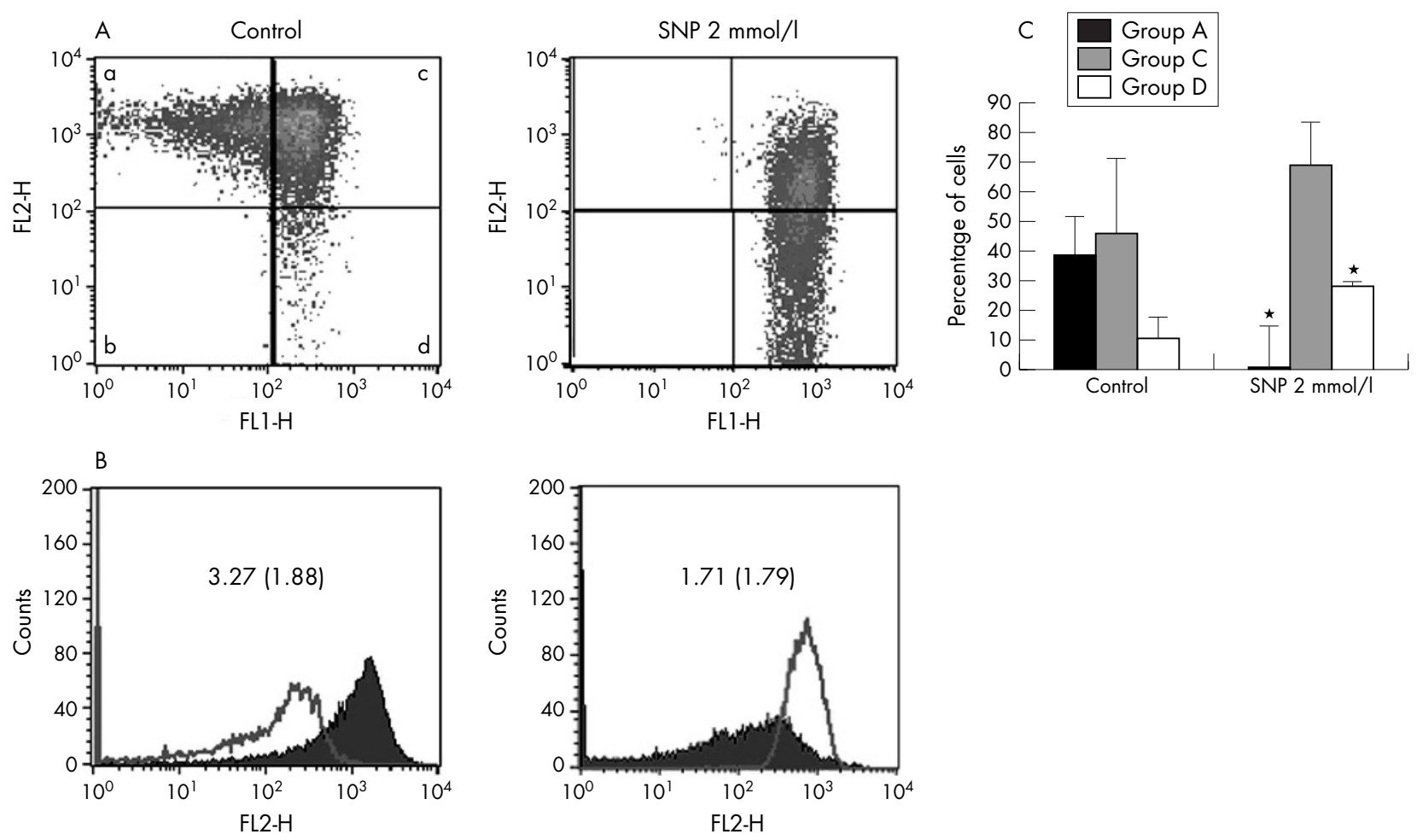

Figure 4 Effect of NO on mitochondrial activity. (A) Fluorescence activated cell sorter analysis of mitochondrial membrane potential in human chondrocytes. Untreated and treated normal chondrocytes $\left(5 \times 10^{5}\right)$ with NO donor (SNP 0.5, 1, and $2 \mathrm{mmol} / \mathrm{l}$ for 5, 12, and 24 hours) were stained with 5,5,6,6-tetrachloro-1,1,3,3-tetraethylbenzimidazole carbocyanide iodide (JC-1) and analysed by flow cytometry. Photomultiplier settings were adjusted to detect JC-1 monomer fluorescence signals on the filter 1 (FL1) detector (green fluorescence) and JC-1 aggregate fluorescence signals on the FL2 detector (red fluorescence). The study showed that chondrocytes could be classified into four subgroups A-D as described in the text. Shown is an example of chondrocytes treated with $2 \mathrm{mM}$ SNP for 5 hours, which shows that SNP increases the population of cells with depolarised mitochondria and decreases that of cells with normal polarisation. (B) Quantification of red and green fluorescence. Histograms represent the JC-1 fluorescence of normal cells (left) and those treated with $2 \mathrm{mM} \mathrm{SNP} \mathrm{for} 5$ hours (right). Green fluorescence (open graph) increases while red fluorescence (solid graph) decreases in the SNP treated chondrocytes, suggesting a reduction of the mitochondrial membrane potential and, therefore, a decrease in the red/ green ratio. Shown is an example at 5 hours. Results are the mean (SD) from six different experiments. (C) Quantification of depolarised chondrocytes. Untreated cells and cells treated ( $5 \times 10^{5}$ normal chondrocytes) with SNP at different concentrations for 5, 12, and 24 hours were analysed by flow cytometry on a FACScan (Becton and Dickinson, Mountain View, CA). The proportion of cells with mitochondrial depolarisation (group D) is greater in SNP treated chondrocytes than in untreated cells. Furthermore, SNP reduced the proportion of cells with normal polarisation (group A). Shown are the results of six experiments at 5 hours. Bars show the mean (SD). ${ }^{*} p \leqslant 0.01$ versus untreated chondrocytes.

proteinase $\mathrm{K}$ cocktail was added to each sample and incubated for 15 minutes at $37^{\circ} \mathrm{C}$ to remove the nucleases. The mixture was extracted with phenol/chloroform/isoamyl

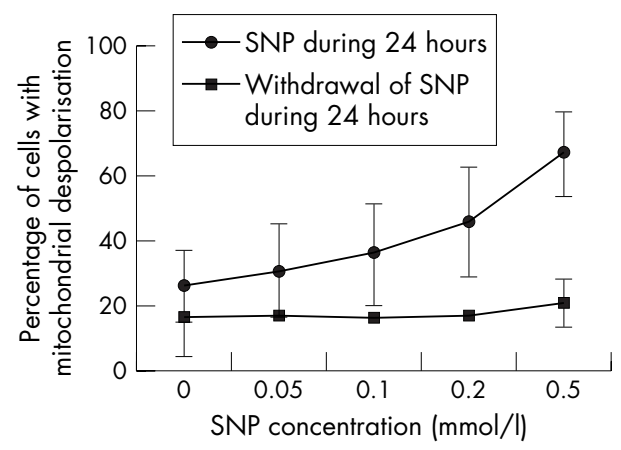

Figure 5 The effect of NO on mitochondrial depolarisation is reversible. Cells $\left(5 \times 10^{5}\right.$ normal human chondrocytes) were treated with $2 \mathrm{mM}$ SNP for 24 hours. The medium was then removed and cells were washed, and new medium without SNP was added. After 24 hours, cells were analysed by flow cytometry on a FACScan (Becton and Dickinson, Mountain View, CA). The proportion of cells with mitochondrial depolarisation (group D) was quantified. The effect of SNP on $\Delta \psi \mathrm{m}$ was reversible. Shown are the results of six experiments at 5 hours. Bars show the mean (SD). alcohol and precipitated with ethanol. The protected fragments were analysed on 6\% TBE-urea gel (Invitrogen, Paisley, Scotland, UK) and by subsequent autoradiography with X-OMAT AR film (Eastman Kodak). To quantify the relative amounts of mRNA of caspases, the protected RNA fragments were scanned by bidimensional laser densitometry (Amersham, Buckinghamshire, UK). Data were standardised to the housekeeping gene L-32, and results were expressed as the percentage of basal gene expression as arbitrary densitometric units.

\section{Western blot}

After appropriate stimulation with different agents, OA cells were washed in ice cold PBS, pH 7.5, and lysed in $0.2 \mathrm{M}$ Tris$\mathrm{HCl}, \mathrm{pH} 6.8$ containing $2 \%$ sodium dodecyl sulphate (SDS), $20 \%$ glycerol, $1 \mu \mathrm{g} / \mathrm{ml}$ cocktail inhibitor, and $1 \mathrm{mM}$ phenyl methyl sulphonyl fluoride (Sigma Chemicals). Samples were boiled for 5 minutes and protein concentrations were determined using a BCA reagent assay (Pierce Chemical Co, Rockford, IL, USA). Protein extract $(30 \mu \mathrm{g})$ was resolved on $12.5 \%$ SDS-polyacrylamide gels and transferred to polyvinylidene difluoride membranes (Immobilon P, Millipore Co, Bedford, MA, USA). Membranes were blocked in Tris buffered saline, pH 7.4 containing $0.1 \%$ Tween-20, and 5\% non-fat dried milk for 60 minutes at room temperature. They were then incubated overnight with mouse antihuman bcl-2 
Table 1 Values of mitochondrial respiratory chain complexes in cultures of normal chondrocytes treated with NO donor compounds (SNP) for 5 hours

\begin{tabular}{|c|c|c|c|c|}
\hline & \multicolumn{2}{|c|}{ Normal chondrocytes } & \multicolumn{2}{|c|}{ Cells treated with $1 \mathrm{mM}$ SNP } \\
\hline & No & Value & No & Value \\
\hline Age (years) & 30 & $59.7(21.8)$ & 11 & $59.7(18.9)$ \\
\hline Proteins (mg/ml) & 30 & $3.6(1.3)$ & 11 & $4.2(1.4)$ \\
\hline CS enzymatic activity ( $\mathrm{nmol} / \mathrm{min} / \mathrm{mg}$ protein) & 29 & $111.7(29.8)$ & 11 & $106.6(26.2)$ \\
\hline \multicolumn{5}{|l|}{ Mitochondrial complex activity $\dagger$} \\
\hline Complex I & 22 & $27.9(13.6)$ & 11 & $22.8(19.1)$ \\
\hline Complex II & 25 & $11.5(5.7)$ & 11 & $10.2(1.81)$ \\
\hline Complex III & 25 & $54.2(13.6)$ & 11 & $46.27(9.7)$ \\
\hline Complex IV & 29 & $53.6(11.9)$ & 11 & $40.2(11.3)^{*}$ \\
\hline
\end{tabular}

Values are the mean (SD).

${ }^{*} \mathrm{p} \leqslant 0.05$ versus normal chondrocytes; + CS corrected complex activity is expressed as $(\mathrm{nmol} / \mathrm{min} / \mathrm{mg}$ protein) $/(\mathrm{CS}$ specific activity) $\times 100$.

$\mathrm{CS}$, citrate synthase; complex I, rotenone sensitive $\mathrm{NADH}$ coenzyme $Q_{1}$ reductase; complex II, succinate dehydrogenase; complex III, antimycin sensitive ubiquinol cytochrome $c$ reductase; complex IV, cyłochrome c oxidase.

(R\&D, Abingdon, UK), $5 \mu \mathrm{g} / \mathrm{ml}$, in fresh blocking solution at $4^{\circ} \mathrm{C}$. After washing, bcl-2 protein was detected by incubation with peroxidase conjugated secondary antibodies and developed using an ECL chemiluminescence kit (Amersham). To assure that equal amounts of total proteins were charged, we also hybridised each membrane with anti- $\alpha$-tubuline (Sigma).

\section{Statistical analyses}

Data analyses were performed with SPSS, version 10.0 (SPSS, Chicago, IL). Results are expressed as the mean (SD). Cells from different donors were not pooled in any experiment. Comparisons between groups were carried out using the

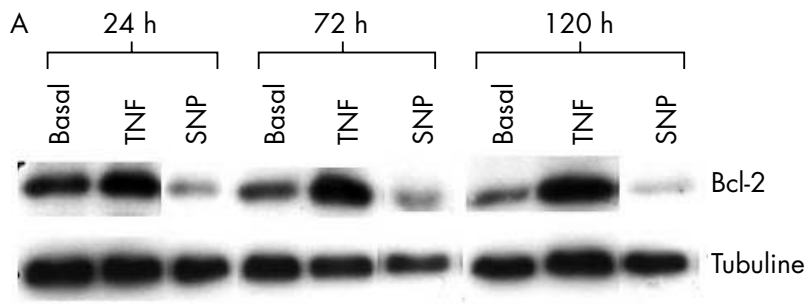

B

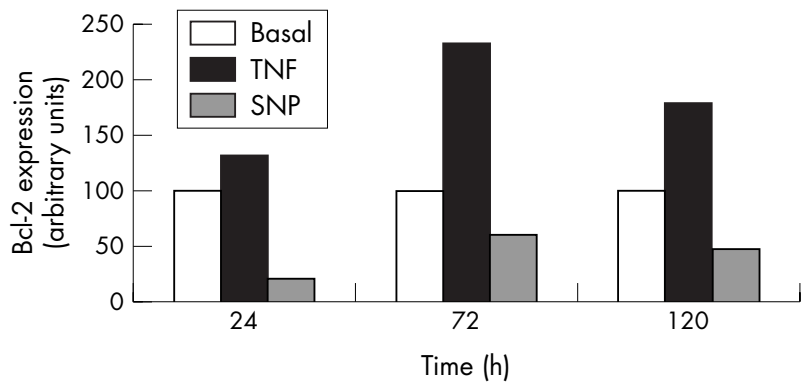

Figure 6 Treatment with NO reduced the activation of the bcl- 2 protein on human chondrocytic cells. (A) Confluent OA chondrocytes were incubated for the indicated times $(24,72$, and 120 hours) in basal conditions or in the presence of SNP $(0.5 \mathrm{mmol} / \mathrm{l})$ or TNF $\alpha(10 \mathrm{ng} / \mathrm{ml})$. Aliquots of total cell lysates were subjected to SDS-polyacrylamide gel electrophoresis, and immunoblotting was performed using the anti-bcl-2 antibody as described in "Materials and methods". This autoradiograph is representative of two experiments. (B) Densitometric analyses of the bands were conducted by computerised laser densitometry and normalised to tubuline. Values are expressed as the percentage over control. TNF $\alpha$ was used as a positive control and a comparator stimulus.
Mann-Whitney two tailed U test or Student's two tailed $t$ test. Values of $p \leqslant 0.05$ were considered significant.

\section{RESULTS}

\section{Effect of NO on chondrocyte survival}

Dose-response and time course analyses of SNP treated normal human chondrocytes showed that this NO donor compound induces chondrocyte apoptosis. Incubation of chondrocytes with SNP at doses higher than $1 \mathrm{mmol} / \mathrm{l}$ for 12 hours significantly increased the number of apoptotic cells in culture (fig 1). The morphological changes induced by SNP in human chondrocytes (for example, condensation, margination, and fragmentation of the genomic DNA) were characteristic of apoptosis. Furthermore, changes in the cytoplasmic membrane, such as bubbles, were detected (fig 2).

Studies carried out in normal chondrocytes showed that $0.5 \mathrm{mM}$ SNP elicited the mRNA expression of caspase- 3 and caspase-7 in a dose and time dependent manner (fig 3). There was a rapid rise by 6 hours after stimulation that began to diminish by 12 hours and reached basal levels at 48 hours. Values at 12 hours versus basal level were: caspase-3, 142\% and caspase-7, 133\%. In contrast, SNP did not modify caspase- $1,-2,-5,-6,-8$, or granzyme B

\section{Effect of NO on mitochondrial function}

Dose-response and time course analyses of treatment with SNP at 0.5, 1, and $2 \mathrm{mmol} / \mathrm{l}$ for 5,12 , and 24 hours demonstrated that such treatment with SNP reliably and significantly alters mitochondrial function (fig 4). The study showed that chondrocytes could be classified into the following four subpopulations: group A, chondrocytes with high red and low green fluorescence (cells with normal mitochondrial polarisation); group B, chondrocytes with low red and low green fluorescence (debris and dead cells); group $\mathrm{C}$, chondrocytes with high red and high green fluorescence (cells with normal mitochondrial polarisation and cells with mitochondrial depolarisation); and group D, chondrocytes with low red and high green fluorescence (cells with mitochondrial depolarisation). The relative ratio of red/green fluorescence (ratio of normal mitochondrial polarisation to mitochondrial depolarisation) intensity values showed that in normal human chondrocyte cultures $2 \mathrm{mM}$ SNP at 5 hours decreased the ratio of red/green fluorescence in comparison with untreated cells (mean (SD) 1.71 (1.79) v 3.27 (1.88); $\mathrm{p} \leqslant 0.01$; fig $4 \mathrm{~B})$. Further analysis showed a reduction in the cell population $(39.2(13.1) \% v 1.27(1.02) \%$; $\leqslant 0.01)$ with normal mitochondrial polarisation (fig 4C). In addition, $2 \mathrm{mM}$ SNP caused an increase in the cell population (10.63 
$(7.3) \% \quad v \quad 28.68 \quad(17.53) \% ; \quad p \leqslant 0.05)$ with mitochondrial depolarisation (fig 4C). This effect on mitochondrial depolarisation was reversible (fig 5).

In relation to the enzymatic activity of the MRC, SNP significantly reduced the activity of complex IV (table 1) in normal human chondrocytes. However, SNP did not affect the activity of complexes I, II, or III, or that of CS.

The Bcl-2 family of proteins are ubiquitous regulators of cell death. The mechanism of action of several member of this family appears to involve mitochondria. Bcl-2 exerts at least some of its anti-apoptotic effects by regulating mitochondrial homoeostasis, in particular by maintaining the mitochondrial-cytosolic coupling of oxidative phosphorylation and the $\Delta \psi \mathrm{m}$. Normal chondrocytes do not contain bcl-2 protein and SNP did not affect its basal level. However, basal levels of bcl-2 protein in OA chondrocytes were increased and they were down regulated by SNP at $0.5 \mathrm{mmol} / \mathrm{l}$ at 24 hours (fig 6).
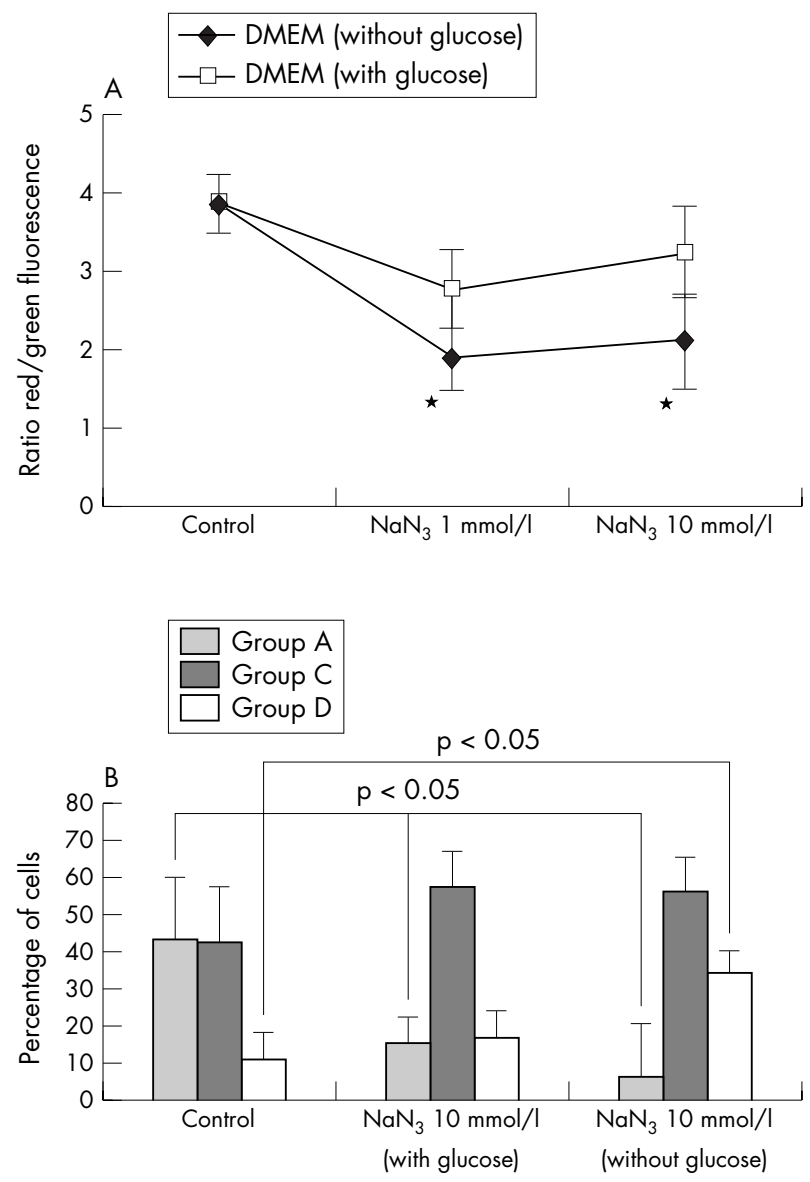

Figure 7 Effect of MRC inhibitor on $\Delta \psi \mathrm{m}$. (A) Normal human chondrocytes $\left(5 \times 10^{5}\right)$ were incubated with $\mathrm{NaN}_{3}$ for 5,12 , and 24 hours. Cells were then analysed by flow cytometry to quantify the $\Delta \psi \mathrm{m}$. Results are shown as the ratio of red/green fluorescence. Shown are the results of six experiments at 5 hours. Bars show the mean (SD). $\mathrm{p}=0.05$ treated $v$ untreated chondrocytes. See "Materials and methods" for a description of the complexes. (B) Quantification of depolarised chondrocytes. Untreated and treated cells $\left(5 \times 10^{5}\right.$ normal human chondrocytes) with $\mathrm{NaN}_{3}$ at different concentrations for 5, 12, and 24 hours were analysed by flow cytometry on a FACScan. $\mathrm{NaN}_{3}$ reduced the proportion of cells with normal polarisation in chondrocytes (group A) cultured in medium with and without glucose. However, the proportion of cells with mitochondrial depolarisation (group D) was higher in chondrocytes stimulated with $\mathrm{NaN}_{3}$ and cultured in medium without glucose. Shown are the results of six experiments at 5 hours. Bars show the mean (SD). ${ }^{*} p \leqslant 0.05$ treated $v$ untreated chondrocytes.

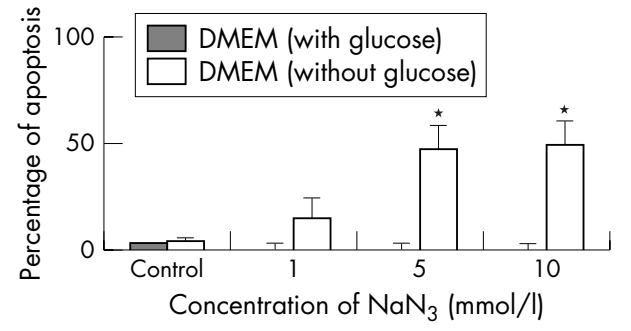

Figure 8 Effect of an MRC inhibitor on chondrocyte apoptosis. Normal human chondrocytes $\left(5 \times 10^{5}\right)$ were cultured in DMEM and glucose-free DMEM, and incubated with $\mathrm{NaN}_{3}$ (a mitochondrial inhibitor of complex IV) for 12,24, and 48 hours. Cells were then analysed by flow cytometry to quantify the percentage of apoptosis. Shown are the results of six experiments at 24 hours. Bars show the mean (SD). ${ }^{*} p=0.05$ treated $v$ untreated chondrocytes. See "Materials and methods" for a description of the technique.

\section{Effect of MRC inhibitors on $\Delta \psi \mathrm{m}$ and apoptosis}

The kinetic results showed that 1 and $10 \mathrm{mM} \mathrm{NaN}_{3}$ at 5 and 24 hours slightly reduced the ratio of red/green fluorescence (fig 7A). A detailed examination of the populations showed that $\mathrm{NaN}_{3}$ caused a reduction in the percentage of cells with normal mitochondrial polarisation $\left(\mathrm{NaN}_{3}\right.$ at $10 \mathrm{mmol} / \mathrm{l}: 15.90$ (12.05)\% $v$ control: 43.45 (15.2)\%; $\mathrm{p} \leqslant 0.05)$. However, it did not modify the percentage of cells with mitochondrial depolarisation (fig 7B). Glucose is metabolised by mitochondria and participates in maintaining the $\Delta \psi \mathrm{m}$. The culture of chondrocytes with glucose-free medium did not alter the $\Delta \psi \mathrm{m}$ of chondrocytes. In contrast, deprivation of glucose increased the effect of $\mathrm{NaN}_{3}$ on $\Delta \psi \mathrm{m}$ and on the percentage of cells with mitochondria depolarisation (fig 7).

To test the significance of complex IV inhibition on apoptosis we also carried out experiments using $\mathrm{NaN}_{3}$. The results showed that the inhibition of complex IV with $\mathrm{NaN}_{3}$ at 1,5 , and $10 \mathrm{mmol} / \mathrm{l}$ at 12,24 , and 48 hours did not induce significant apoptosis of chondrocytes (fig 8). However, deprivation of glucose in the culture medium significantly increased the percentage of apoptotic cells.

\section{DISCUSSION}

As far as we know, this is the first study analysing the effect of exogenous NO on the enzymatic activity of MRC complexes I-IV, CS, and on $\Delta \psi \mathrm{m}$ in human normal articular chondrocytes, and the possible implications for apoptosis. We measured respiratory chain complexes normalised to CS activity because this enzyme is considered to be a marker of mitochondrial mass and because the specific respiratory complex to CS ratio indicates whether differences in complex activities are due to the enrichment in mitochondrial proteins or to a change in mitochondrial metabolic function. ${ }^{7}$ Furthermore, the accurate assessment of $\Delta \psi \mathrm{m}$ within living cells under physiological conditions is essential for an understanding of the role of mitochondria in altered cell function after the inhibition of mitochondrial enzymes. ${ }^{34}$

NO seems to have both beneficial and detrimental effects on the cellular death or survival outcome; the exact role of $\mathrm{NO}$ in this case is not fully understood. A direct investigation of the function of exogenous NO production on chondrocytes has been hampered by the lack of uniformity that exists between the different types of NO donor compounds. ${ }^{33}$ We used SNP as the NO donor compound because it is used in the majority of studies. Our results confirmed that SNP reduces chondrocyte survival and induces cell death, with morphological changes characteristic of chondrocyte apoptosis. Furthermore, we demonstrated that SNP induces the mRNA expression of caspase- 3 and caspase- 7 only, and reduces the synthesis of bcl-2, an anti-apoptotic molecule. 
These results found in human normal chondrocytes are in agreement with other reports using rabbit $^{35}$ and human OA chondrocytes. ${ }^{36}$ In contrast, TNF increased bcl-2 synthesis in chondrocytes, and cultured cells were resistant to apoptosis by $\mathrm{TNF} \alpha$ alone, but combined treatment of $\mathrm{TNF} \alpha$ with actinomycin D reduced the bcl-2 synthesis and increased apoptosis in a dose and time dependent manner (personal data).

In mitochondrial oxidative phosphorylation, electron transport is coupled along four enzyme complexes (I-IV) in the mitochondrial inner membrane, and ATP is synthesised from ADP at complex V (ATP synthase). NO is a multifunctional molecule that mediates various biological processes. In chondrocytes the most direct effect of NO seems to be the suppression of energy metabolism. In rabbit and human chondrocytes several investigators have reported that SNP suppresses mitochondrial respiration by reducing oxygen consumption and by diminishing ATP levels. ${ }^{31-33}$ However, studies elucidating the effect of NO or SNP on the MRC activity of normal human chondrocytes have not yet been reported. We have shown that SNP reduces the activity of complex IV exclusively.

The proton electrochemical gradient potential is the sum of the $\Delta \psi \mathrm{m}$ and the proton gradient. Because the $\mathrm{pH}$ component is generally small, $\Delta \psi \mathrm{m}$ reflects the functional status of the mitochondria. ${ }^{26}{ }^{34}$ Some reports suggest that the activity of both caspases and apoptosis depends on the reduction of $\Delta \psi \mathrm{m}$ and/or the induction of mitochondrial permeability transition. We found that SNP mediates mitochondrial depolarisation in normal human chondrocytes, as demonstrated both by a rise in green fluorescence (mitochondrial depolarisation) and by a drop in red fluorescence (normal mitochondrial polarisation).

A possible explanation for the finding that SNP induces apoptosis is the interaction of additional reactive oxygen species (ROS) that may be concomitantly produced as a consequence of the NO donor compound itself. An increased intracellular level of ROS is a demonstrated condition under which the intracellular redox status of the chondrocyte can directly mediate whether NO will become cytotoxic through the formation of other reactive nitrogen species (RNS). ${ }^{38}$ Then, the action of NO on MRC and $\Delta \psi \mathrm{m}$ activity can modulate the production of ROS by mitochondria and the increased cytotoxicity that is associated with $\mathrm{NO}$ and with some RNS, such as peroxynitrite. Peroxynitrite reacts with mitochondrial membranes significantly inhibiting the activities of complexes I, II, and III. Because we found that SNP only inhibits complex IV and Del Carlo et al reported that SNP remains cytotoxic even in the presence of ROS scavengers, ${ }^{33}$ it is unlikely that SNP uses this mechanism of action.

It has been reported that $\mathrm{NO}$ also directly inhibits complex IV by the reversible binding of NO to cytochrome $c$ oxidase in competition with oxygen. ${ }^{38} 39$ One approach for determining if the cell death caused by SNP is mediated directly by the inhibition of complex IV is to determine the effect of $\mathrm{NaN}_{3}$ on cytotoxicity and mitochondrial activity. Our results showed that the inhibition of complex IV with $\mathrm{NaN}_{3}$ modified the $\Delta \psi \mathrm{m}$ or the survival of chondrocytes. $\mathrm{NaN}_{3}$ induced apoptosis in both conditions-that is, cells cultured with and without glucose, but its effect was greater when glucose was absent. A possible explanation is that the inhibition of complex IV exclusively is not enough to induce apoptosis and other cellular events, such as a reduction in the intake of glucose, need to be present to induce it.

Another possible mechanism to explain the effect of SNP on cell survival and mitochondrial activity is that involving the products of the decomposition of SNP, such as the cyanide anion. It has been reported that cyanide induces irreversible inhibition of complex IV. ${ }^{37}{ }^{39}$ However, we have demonstrated that the effect of SNP on mitochondrial activity is reversible. Furthermore, cyanide did not modify mitochondrial polarisation and it did not induce chondrocyte apoptosis (data not shown).

Cartilage is a tissue influenced by acting factors both in the epiphysial zone (deep zone) and synovial fluid or synovium (superficial zone). Several lines of experimentation suggest that provision of glucose and oxygen supplied from synovial fluid may be critical, particularly for chondrocytes in the deep zone. ${ }^{40}{ }^{41}$ Recent studies suggest that glucose and oxygen may be particularly critical in cellular apoptosis. ${ }^{42}$ In our case, chondrocytes from the superficial and deep zones were kept in standard media with high glucose concentration ( $4.5 \mathrm{mmol} / \mathrm{l}$ ) and aerobic conditions that could lead cells to obtain their energy predominantly from an anaerobic glycolysis and to cells which are more resistant to apoptosis. Thus, we showed that the culture of chondrocytes in medium without glucose did not modify the survival, but both the inhibition of complex IV and glucose deprivation increased the percentage of apoptotic chondrocytes and reduced the red/green ratio showing a profile of depolarisation very similar to the SNP profile (reduced number of cells with normal polarisation and increased number cells with mitochondrial depolarisation).

In summary, SNP, a traditional NO donor compound, induces morphological changes characteristic of chondrocyte apoptosis. Furthermore, SNP induced an increase of caspase-3 and caspase-7 mRNA and down regulation of the bcl-2 protein. It also reduces the enzyme mitochondrial activity of complex IV, and reduces $\Delta \psi \mathrm{m}$. Because peroxynitrate inhibits complexes I, II, and III, our data support the idea that the effect of SNP on apoptosis is not through peroxynitrate production. Because the inhibition of complex IV modified mitochondrial activity and cell survival, our results suggest that the effect of SNP on apoptosis is mediated by reduction of its enzymatic activity.

\section{ACKNOWLEDGEMENTS}

We thank Ms Pilar Cal Purriños for her expert secretarial assistance and express appreciation to Dr Ramallal and Mrs Lourdes Sanjurjo from the Department of Orthopaedics and to Dr J Sanchez from the Tissue Bank (OCT) of the CHU Juan Canalejo, for providing cartilage samples.

This study was supported by grants from Fondo Investigación Sanitaria-Spain; Expediente 01/054, 02/1700 and 02/1635 and by a grant from Secretaria I+D+I. Xunta de Galicia. PGIDIT02SAN91603PR. MC de Andres's work was supported by FIS-Spain: BEFI 02/9012. B Carames and A Bonilla are recipients of a grant from Secretaria Xeral I+D (PGIDIT02PXIC91604PN and PGIDIT03BTF91601PR). E. Maneiro's work was supported by FIS, Programa Investigadores del SNS. MJ López Armada was supported by Ministerio de Ciencia Tecnologia, Programa Ramon y Cajal.

\section{Authors' affiliations}

E Maneiro, M J López-Armada, M C de Andres, B Caramés, A Bonilla, F Galdo, F J Blanco, Laboratory of Investigation, Rheumatology Division, Juan Canalejo Hospital, Xubias 84, 15006-A Coruña, Spain

M A Martín, P del Hoyo, J Arenas, Laboratory of Investigation, Hospital 12 de Octubre, Madrid, Spain

\section{REFERENCES}

1 López-Armada MJ, Carames B, Cillero-Pastor B, Blanco FJ. Fisiopatología de la artrosis. Rev Esp Reum 2004;31:399-93.

2 Pritzker KPH. Pathology of osteoarthritis. In: Brandt KD, Doherty M, Lohmander LS, eds. Osteoarthritis. New York: Oxford University Press, 1998:50-61.

3 Blanco FJ, Guitian R, Vazquez-Martul E, de Toro FJ, Galdo F. Osteoarthritis chondrocytes die by apoptosis. A possible pathway for osteoarthritis pathology. Arthritis Rheum 1998;41:284-9.

4 Hashimoto S, Ochs R, Komiya S, Lotz M. Linkage of chondrocyte apoptosis and the cartilage degradation in human ostearthritis. Arthritis Rheum 1998;41:1632-8. 
5 Kosel S, Hofhaus G, Maassen A, Vieregge P, Graeber MB. Role of mitochondria in Parkinson disease. Biol Chem 1999;380:865-70.

6 Leonard JV, Schapira, AH. Mitochondrial respiratory chain disorders I: mitochondrial DNA defects. Lancet 2000;355:299-304.

7 Maneiro E, Martín MA, De Andrés MC, López-Armada MJ, FernandezSueiro JL, Del Hoyo P, et al. Mitochondrial respiratory activity is altered in OA human articular chondrocytes. Arthritis Rheum 2003;48:700-8.

8 Green DR, Reed JC. Mitochondria and apoptosis. Science 1998;281:1309-12.

9 Loeffler M, Kroemer G. The mitochondrion in cell death control: certainties and incognita. Exp Cell Res 2000;256:19-26.

10 Kroemer G, Zamzami N, Susin SA. Mitochondrial control of apoptosis. Immunol Today 1997:8:44-51.

11 Zamzani N, Marchetti P, Castedo M, Zanin C, Vayssiere JL, Petit PX, et al. Reduction in mitochondrial potential constitutes an early irreversible step of programmed lymphocyte death in vivo. J Exp Med 1995;181:1661-72.

12 Petit PX, Lecoeur H, Zorn E, Dauguet C, Mignotte B, Gougeon ML. Alterations in mitochondrial structure and function are early events of dexamethasoneinduced thymocyte apoptosis. J Cell Biol 1995;130:157-67.

13 Vayssiere JL, Petit PX, Risler Y, Mignotte B. Commitment to apoptosis is associated with changes in mitochondrial biogenesis and activity in cell lines conditionally immortalized with simian virus 40. Proc Natl Acad Sci USA 1994;91:11752-6.

14 Petit PX, Zamzami N, Vayssiere JL, Mignotte B, Kroemer G, Castedo M. Implication of mitochondria in apoptosis. Mol Cell Biochem 1997;174:185-8.

15 Crompton $\mathbf{H}$. The mitochondrial permeability transition pore and its role in cell death. Biochem J 1999;341:233-49.

16 Nicotera P, Leit M, Ferrando-May E. Intracellular ATP, a switch in the decision between apoptosis and necrosis. Toxicol Lett 1998;258:215-21.

17 Vander Heiden MG, Chandel NS, Li XX, Schumacker PT, Colombini M, Thompson $C B$. Outer mitochondrial membrane permeability can regulate coupled respiration and cell survival. Proc Natl Acad Sci USA 2000;97:4666-71.

18 Kluck RM, Bossy-Wetzel E, Green DR, Newmeyer DD. The release of cytochrome c from mitochondria: a primary site for $\mathrm{Bcl}-2$ regulation of apoptosis. Science 1997; 275:1132-6.

19 Cleeter MW, Cooper JM, Darley-Usmar VM, Moncada S, Schapira AH. Reversible inhibition of cytochrome $c$ oxidase, the terminal enzyme of the mitochondrial respiratory chain, by nitric oxide. Implications for neurodegenerative diseases. FEBS Lett 1994;345:50-4.

20 Lotz M. The role of nitric oxide in articular cartilage damage. Rheum Dis Clin North Am 1999;25:269-82.

21 Amin AR, Dave M, Attur M, Abramson SB. COX, NO, and cartilage damage and repair. Curr Opin Rheumatol 2000;2:447-53.

22 Studer R, Jaffurs D, Stefanovic-Racic M, Robbins PD, Evans CH. Nitric oxide in osteoarthritis. Osteoarthritis Cartilage 1999;7:377-9.

23 Blanco FJ, Ochs R, Schwarta H, Lotz M. Chondrocyte apoptosis induced by nitric oxide. Am J Pathol 1995; 146:75-85.

24 Horton WE Jr, Feng L, Adams C. Chondrocyte apoptosis in development, aging and disease. Matrix Biol 1998;17:107-15.

25 Kim HA, Lee YJ, Seong SC, Choe KW, Song YW. Apoptotic chondrocyte death in human osteoarthritis. J Rheumatol 2000;27:455-62.
26 Almeida A, Almeida J, Bolaños JP, Moncada S. Different responses of astrocytes and neurons to nitric oxide: the role of glycolytically generated ATP in astrocyte protection. Proc Natl Acad Sci USA 2001;98:15294-9.

27 Ushmorov A, Ratter F, Lehmann V, Droge W, Schirrmacher V, Umansky V. Nitric-oxide-induced apoptosis in human leukemic lines requires mitochondrial lipid degradation and cytochrome $C$ release. Blood 1999;93:2342-52.

28 Brown GC. Nitric oxide regulates mitochondrial respiration and cell functions by inhibiting cytochrome oxidase. FEBS Lett 1995:369:136-9.

29 Takabayashi A, Kawai Y, Iwata S, Kanai M, Denno R, Kawada K, et al. Nitric oxide induces a decrease in the mitochondrial membrane potential of peripheral blood lymphocytes, especially in natural killer cells. Antioxid Redox Signal, 2000;2:673-80.

30 Moriya R, Uehara T, Nomura Y. Mechanism of nitric oxide-induced apoptosis in human neuroblastoma SH-SY5Y cells. FEBS Lett 2000;484:253-60.

31 Tomita M, Sato RF, Nishikawa M, Yamano Y, Inove M. Nitric ixide regulates mitochondrial respiration and functions of articular chondrocytes. Arthritis Rheum 2001:44:96-106.

32 Johnson K, Jung A, Andreyev A, Dykens J, Terkeltaub R. Mitochondrial oxidative phosphorylation is a downstream regulator of nitric oxide effects on chondrocyte matrix synthesis and mineralization. Arthritis Rheum 2000;43:1560-70.

33 Del Carlo M, Loeser RF. Nitric oxide-mediated chondrocyte cell death requires the generation of additional reactive oxygen species. Arthritis Rheum 2002;46:394-403.

34 Gottlieb RA, Granville DJ. Analyzing mitochondrial changes during apoptosis. Methods 2002;26:341-7.

$35 \mathrm{Kim}$ SJ, Ju JW, Oh CD, Yoon YM, Song WK, Kim JH, et al. ERK-1/2 and p38 kinase oppositely regulate nitric oxide-induced apoptosis of chondrocytes in association with p53, caspase-3 and differentiation status. J Biol Chem 2002;277: 1332-9.

36 Notoya K, Jovanovic DV, Reboul P, Martel-Pelletier J, Mienau F, Pelletier JP. The induction of cell death in human osteoarthritis chondrocytes by nitric oxide is related to the production of prostaglandin E2 via the induction of cyclooxygenase-2 J Immunol 2000; 165:3402-10.

37 Bates JN, Baker MT, Guerra R, Harrinson DG. Nitric oxide generation from nitroprusside by vascular tissue: evidence that reduction of the nitroprusside anion and cyanide loss are required. Biochem Pharmcol 1991;42(suppl):S157-65.

38 Lizasoain I, Moro MA, Knowles RG, Darley-Usmar V, Moncada S. Nitric oxide and peroxynitrite exert distinct effects on mitochondrial respiration which are differently blocked by glutathione or glucose. Biochem J 1996:314:877-80

39 Leary SC, Hill B, Lyons CN, Carlson CG, Michaud D, Kraft CS, et al. Chronic treatment with azide in situ leads to an irreversible loss of cytochrome $c$ oxidase activity via holoenzyme dissociation. J Biol Chem 2002;27:11321-8.

40 Otte P. Basic cell metabolism of articular cartilage. Manometric studies. Z Rheumatol 1991;50:304-12.

41 Lee RB, Urban JP. Evidence for a negative Pasteur effect in articular cartilage. Biochem J 1997;321:95-102.

42 Borderie D, Le Marechal H, Ekindjian OG, Hernvann A. Nitric oxide modifies glycolytic pathways in cultured human synoviocytes. Cell Biol Int 2000;24:285-9. 